\title{
Het zelfoordeel van buitenlandse artsen over hun VWS-assessment- competenties bij de start van de opleiding geneeskunde in Nederland
}

\author{
P.G.P. Herfs • L. Kater • J.R.E. Haalboom
}

Samenvatting Onder verantwoordelijkheid van het ministerie van Volksgezondheid, Welzijn en Sport is voor alle buitenlandse artsen met een buiten de Europese Economische Ruimte (EER) behaald diploma, en die in Nederland werkzaam willen zijn als arts, een assessmentprocedure ontwikkeld. Deze procedure is per 1 december 2005 ingevoerd en beoogt de kwaliteit van de instroom, gemeten naar Nederlandse maatstaven, te verbeteren. Het assessment bestaat uit twee aspecten: toetsing van algemene kennis en vaardigheden (o.a. Nederlandse taalen communicatievaardigheid, Engelse leesvaardigheid, kennis van de ICT, kennis van de Nederlandse gezondheidszorg) en toetsing van medische en klinische kennis en vaardigheden. Er zijn vijf mogelijke uitkomsten: kennis is gelijkwaardig, noodzaak van aanvullend programma van één, twee of drie jaar of van volledige opleiding.

Onderzocht is hoe de buitenlandse artsen, die in de twee jaren voorafgaand aan de invoering van de assessment-procedure via de Commissie Instroom Buitenlandse Artsen (CIBA)-procedure zijn ingestroomd, zelf hun competenties bij de aanvang van hun aanvullende opleiding geneeskunde beoordelen. In totaal werden 157 buitenlandse artsen aangeschreven waarvan 106 (68\%) respondeerden. In het algemeen zijn zij van mening dat het niveau van hun algemene en medische kennis en vaardigheden redelijk aansluit bij de eisen die vanuit de Nederlandse gezondheidszorg gesteld worden. Dit komt echter niet overeen met de indrukken van opleiders. $\mathrm{Zij}$ geven aan dat het grootste probleem de beheersing van de Nederlandse taal is. Verbetering daarvan tijdens de opleiding geneeskunde en zelfs daarna is in hun optiek noodzakelijk.

\section{Inleiding en vraagstelling}

Het ministerie van VWS heeft in samenwerking met de medische faculteiten een assessment-procedure voor buitenlandse artsen ontwikkeld, die op 1 december 2005 in werking is getreden. Vóór die tijd betekende een afwijzende ministeriële beschikking het einde van de bemoeienis van het ministerie van VWS met de buitenlandse arts, die om een bewijs van vakbekwaamheid verzocht had. ${ }^{1-4}$ In feite namen de medische faculteiten de verantwoordelijkheid voor deze afgewezen buitenlandse artsen van het ministerie over. Dit had tot gevolg dat de inpassing van buitenlandse artsen in bestaande onderwijsprogramma's van de acht medische faculteiten niet uniform geregeld was. Iedere faculteit had zijn eigen instroomprogramma. In sommige faculteiten werd ingepast zonder betrouwbare gegevens over de kennis en kunde van de betrokken artsen; de betreffende examencommissies namen dan vaak 'het zekere voor het onzekere'. In andere faculteiten werd de zogenaamde Maastrichtse voortgangstoets of een vergelijkbare toets afgenomen. De nieuwe assessment-procedure heeft aan deze praktijk een einde gemaakt.

In 2002 besloot het ministerie van $\mathrm{VWS}^{1}$ tot "facilitering van medische faculteiten bij het organiseren van aanvullende scholing voor buitenlandse artsen in het kader van het plan van aanpak capaciteit medische beroepsbeoefenaren." Een commissie ${ }^{3}$ ontwikkelde een nieuwe stroomlijn voor buitenlandse artsen, die door het ministerie van VWS werd overgenomen. Aan de totstandkoming van dit in 2003 verschenen rapport ging in 2002 een ronde tafel conferentie vooraf, waar alle

\footnotetext{
${ }^{1}$ Als gevolg van de motie Hermann (Groen Links) aangenomen d. d. 6 dec. 2001 in de Tweede Kamer.
} 
medische faculteiten vertegenwoordigd waren en de problemen met buitenlandse artsen werden geïnventariseerd. Eind 2005 leidde dit tot een uitvoerbaar en gestroomlijnd programma en een plan van aanpak voor alle buitenlandse artsen met diploma en nationaliteit van buiten de EER die in de Nederlandse gezondheidszorg werkzaam willen zijn. ${ }^{5}$

De nieuwe assessment-procedure is weergegeven in het Stroomschema buitenlandse artsen (figuur 1) met de belangrijkste actoren: ministerie van VWS, Centraal Informatiepunt Beroepen in de Gezondheidszorg (CIBG) en de onderwijsinstellingen. Het schema biedt inzicht in de verschillende stappen die buitenlandse artsen moeten doorlopen.

De nieuwe assessment-procedure wijkt in hoge mate af van de werkwijze die vanaf de instelling van de Commissie Instroom Buitenlandse Artsen (CIBA) in 1996 gebruikelijk was. Ook de nagenoeg gelijkwaardig beoordeelde buitenlandse artsen worden nu verplicht deel te nemen aan de nieuwe procedure terwijl voorheen alleen de als niet gelijkwaardig beoordeelden door CIBA werden geplaatst. Dit betekent een verbreding van de doelgroep, waarmee tegemoet gekomen is aan de ernstige bezwaren die kleven aan het supervisietraject voor nagenoeg gelijkwaardige buitenlandse artsen. ${ }^{6}$

De doelstellingen van de assessment-procedure zijn de volgende:

1. verbeterde instroom van gekwalificeerde beroepsbeoefenaren van buiten de EER naar Nederlandse maatstaven in de Nederlandse gezondheidszorg.

2. rechtsgelijkheid voor de aanvragers.

3. eenvoudigere, snellere en transparantere procedure.

4. gericht advies voor aanvullende scholing op basis van toetsen.

5. vermindering van de administratieve lasten.

6. betere resultaten.

De nieuwe assessment-procedure heeft als kenmerken standaardisatie (alle kandidaten van buiten de EER worden gelijk behandeld) en tempo (de procedure voor erkenning kan binnen een half jaar worden afgerond) en bestaat uit een algemene en medische kennis- en vaardighedentoets. De procedure is gebaseerd op de in het rapport van de commissie Splinter gedane aanbevelingen. ${ }^{3}$

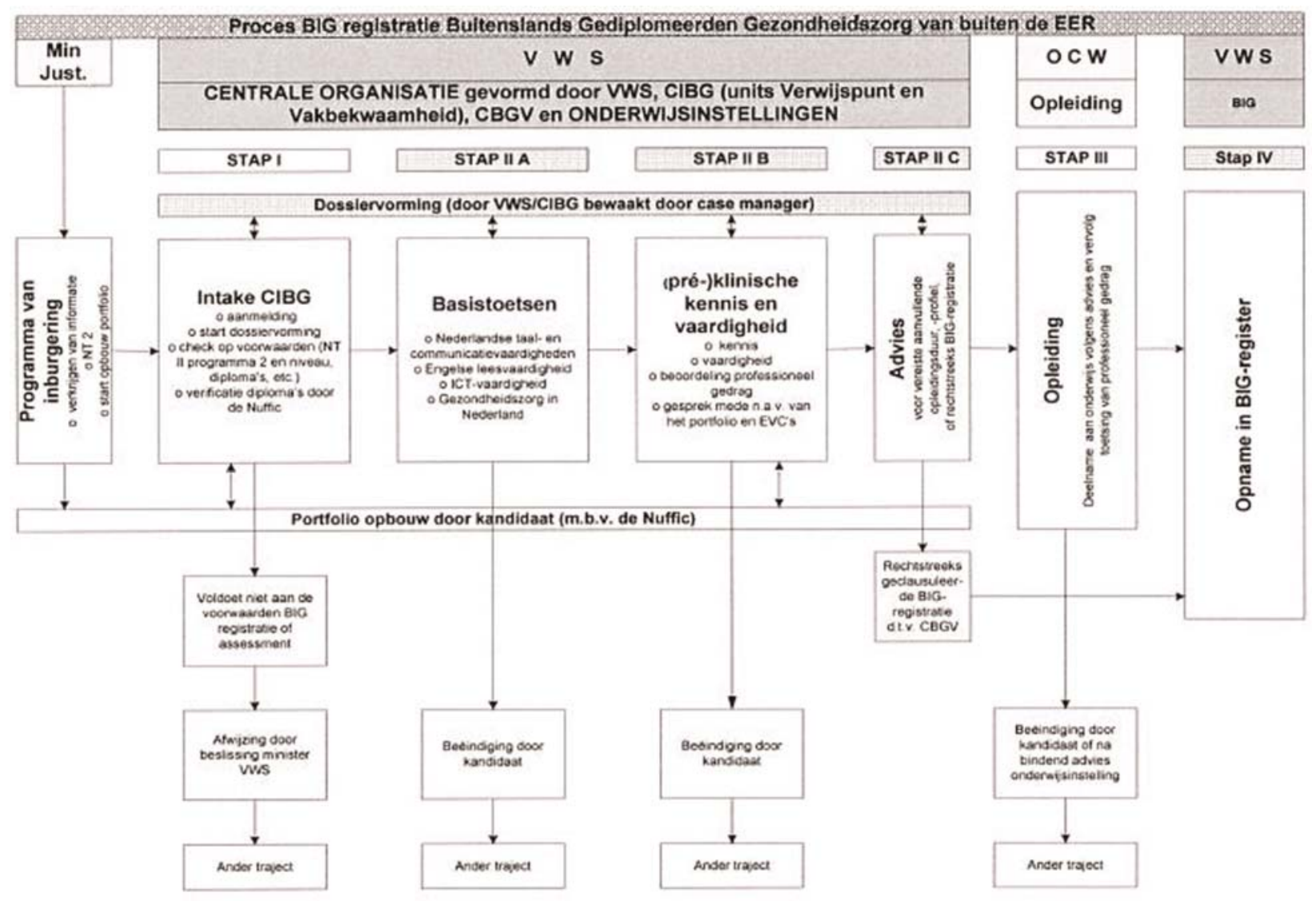

Figuur 1 Stroomschema buitenlandse artsen. (Bron: min. VWS) 
In een recente studie van Tromp et $\mathrm{al}^{7}$ is geconstateerd dat buitenlandse artsen die onder het oude CIBAregime instroomden in de opleiding geneeskunde tekortkomingen vertonen. Tromp et al. benadrukken dat deze buitenlandse artsen zowel tekort schieten in de beheersing van de Nederlandse taal als in professioneel gedrag (communicatie met patiënten, samenwerking met verplegend personeel en collegae, de mate van openstaan voor kritiek, de mate waarin men zijn beperkingen kent, enz.).

De door opleiders gesignaleerde tekortkomingen zijn 'vertaald' in concrete deeltoetsen van de assessment-procedure. Het algemene deel bestaat uit deeltoetsen Nederlandse taal- en communicatievaardigheid, ICTvaardigheden, Engelse leesvaardigheid en kennis van de gezondheidszorg in Nederland. Het medische deel omvat deeltoetsen over kennis van de basisvakken, kennis van de klinische vakken en klinische vaardigheid (stationstoets). Op vrijwillige basis kan een deelnemer een portfolio opstellen. De beoordeling van de toetsen kan (op basis van eventueel geconstateerde deficiënties) tot één van de volgende uitkomsten leiden:

1. de kandidaat hoeft geen aanvullend medisch onderwijs te volgen, maar moet voor de beoordeling van professioneel gedrag een stage van 12 weken volgen.

2. de kandidaat moet één jaar aanvullend medisch onderwijs volgen.

3. de kandidaat moet twee jaar aanvullend medisch onderwijs volgen.

4. de kandidaat moet drie jaar aanvullend medisch onderwijs volgen.

5. er wordt geen vrijstelling van medisch onderwijs verleend; de volledige studie geneeskunde moet worden doorlopen.

In de nieuwe assessment-procedure worden alle buitenlandse artsen voorafgaand aan de toelating tot een opleiding geneeskunde op kennis en kunde getoetst. Iedere buitenlandse arts doorloopt dezelfde procedure, waarbij de duur van de eventuele aanvullende programma's, of de uitsluiting daarvan, afhankelijk is van de geleverde prestaties. De examencommissies van de acht medische faculteiten conformeren zich aan het oordeel van de commissie die belast is met de uitvoering van de assessment-procedure en waarin alle faculteiten zijn vertegenwoordigd. Onder het nieuwe regime maakt het niet meer uit aan welke medische faculteit een buitenlandse arts wordt toegewezen. Met de nieuwe assessment-procedure lijkt een belangrijke stap gezet te zijn in de richting van professionalisering van het beoordelen van de vakbekwaamheid van buitenlandse artsen.

Bij de totstandkoming van de nieuwe procedure hebben buitenlandse artsen geen inbreng van betekenis gehad. Het is niet bekend hoe de buitenlandse artsen die nog net vóór de inwerkingtreding van de nieuwe assessment-procedure gestart waren met hun aanvullende medische opleiding, zelf hun getoetste kwaliteiten beoordeeld zouden hebben, indien zij onder de werking van de nieuwe procedure zouden zijn gevallen. In dit onderzoek is geprobeerd op deze vraag een antwoord te krijgen. Om de respondenten zo betrouwbaar mogelijk te laten antwoorden is van te voren gewezen op de anonimiteit en het ontbreken van persoonlijke gevolgen. De vraagstelling van deze studie is te onderzoeken hoe instromende buitenlandse artsen oordelen over hun algemene en medische competenties en of deze oordelen sporen met die van de opleiders.

\section{Methode}

In september 2004 en 2005 zijn de laatste twee cohorten van in totaal 157 buitenlandse artsen via de oude CIBAregeling ingestroomd en aan één van de acht medische faculteiten in Nederland toegewezen. Toelating vond plaats nadat tenminste gecontroleerd was of de buitenlandse arts geslaagd was voor het examen Nederlands als tweede taal (Nt2), beschikte over een artsdiploma behaald buiten de EER en een permanente verblijfsvergunning in Nederland had. Via tussenkomst van de CIBA (namen en adresgegevens) zijn deze voltallige cohorten in maart 2006 benaderd.

Naast de vragenlijst kregen deze ingestroomde buitenlandse artsen ook achtergrondinformatie over de nieuwe assessment-procedure. De vragenlijst (zie box 1) bevatte acht vijf-puntsvragen over de competenties (basisvaardigheden en medische kennis en vaardigheden) bij de start van de opleiding geneeskunde en één open vraag. Deze vragenlijst is van tevoren door buitenlandse artsen die niet in dit onderzoek betrokken zijn getest op duidelijkheid. De waarde 1 staat voor 'sloot geheel niet aan'; de waarde 5 voor 'sloot goed aan'. De waardes 2, 3 en 4 zijn tussenwaarden. Waarde 3 is neutraal geformuleerd en staat voor 'sloot niet goed, maar ook niet slecht aan'. Verder bevatte de vragenlijst één open vraag die gericht was op een (of meer) tekortkoming( en) waar de buitenlandse arts bij de start van de opleiding geneeskunde de meeste hinder van ondervonden had. Bij de statistische berekeningen is gebruik gemaakt van SPSS. ${ }^{8}$

Box 1 Vragenlijst over de inpassing van buitenlandse artsen. Als u vanuit uw huidige positie terugkijkt naar uw kwaliteiten bij aanvang van de studie geneeskunde in Nederland, in hoeverre sloten deze kwaliteiten dan aan bij de eisen die de Nederlandse gezondheidszorg stelt? Deze vraag heeft betrekking op de volgende kwaliteiten: 


\begin{tabular}{|c|c|c|c|c|c|}
\hline & \multicolumn{3}{|c|}{ Sloot geheel niet aan 1} & \multicolumn{2}{|c|}{ Sloot goed aan } \\
\hline & - & & $--1+$ & + & ++ \\
\hline Uw Nederlandse taal- en communicatievaardigheid & 1 & 2 & 3 & 4 & 5 \\
\hline Uw leesvaardigheid Engels & 1 & 2 & 3 & 4 & 5 \\
\hline Uw kennis van de ICT & 1 & 2 & 3 & 4 & 5 \\
\hline Uw kennis van de Nederlandse gezondheidszorg & 1 & 2 & 3 & 4 & 5 \\
\hline Uw medische kennis op het niveau van het Nederlands artsexamen & 1 & 2 & 3 & 4 & 5 \\
\hline Uw klinische kennis op het niveau van het Nederlands artsexamen & 1 & 2 & 3 & 4 & 5 \\
\hline Uw klinische vaardigheid op het niveau van het Nederlands artsexamen & 1 & 2 & 3 & 4 & 5 \\
\hline Uw overige eerder verworven competenties 2 & 1 & 2 & 3 & 4 & 5 \\
\hline
\end{tabular}

1 De schaalwaarden hebben de volgende betekenis:

$1=$ sloot geheel niet aan; $2=$ sloot niet aan; $3=$ sloot niet goed, maar ook niet slecht aan; $4=$ sloot redelijk aan; $5=$ sloot goed aan

2 Hiermee wordt gedoeld op uw medische kennis en werkervaring opgedaan in het land van herkomst en/of het land waar u bent opgeleid

Wat waren de tekortkomingen waar $\mathrm{u}$ de meeste hinder van ondervonden hebt? De tekortkoming (en) kan (kunnen) op een heel ander terrein liggen dan de genoemde terreinen.

Antwoord:

Op grond van de ervaringen van de acht faculteiten met de inpassing van buitenlandse artsen in voorgaande jaren was de verwachting dat er op de onderzochte variabelen geen significante verschillen gevonden zouden worden tussen studenten van de acht medische faculteiten.

\section{Resultaten}

De respons

Van de 157 verzonden vragenlijsten zijn er 106 teruggestuurd; een respons van $68 \%$. In tabel 1 is de respons per universiteit weergegeven.

Bespreking van de resultaten op de gesloten vragen

Tabel 2 toont de gemiddelde scores, weergegeven per universiteit en per variabele, van de buitenlandse artsen die ingestroomd zijn aan de acht medische faculteiten. Er zijn geen significante verschillen gevonden. Wel zijn enkele opmerkingen te maken: op de variabele Nederlandse taalen communicatievaardigheid scoren studenten van de Universiteit Maastricht een vol punt lager $(3,40)$ dan die van de Universiteit Utrecht $(4,40)$. Op de variabele Engelse leesvaardigheid scoren studenten van de Radboud Universiteit Nijmegen lager $(3,59)$ dan de studenten van de Universiteit van Amsterdam $(4,46)$. Op de variabele kennis van ICT scoren de studenten van de Radboud Universiteit Nijmegen lager $(3,56)$ dan die van de Universiteit Utrecht $(4,50)$. Tabel 3 geeft een overzicht van de gemiddelde score per variabele over de totale steekproef.
De gemiddelde scores op de onderdelen van de algemene kennis- en vaardighedentoets liggen niet significant lager dan de gemiddelde scores op de medische kennis- en vaardighedentoets. De laagste score betreft de kennis van de Nederlandse gezondheidszorg. Nijmegen scoort het laagste $(3,90)$ en Rotterdam het hoogste $(4,21)$. De aangetroffen verschillen tussen de gemiddelde scores per instelling (zie tabel 4) zijn niet significant (ANOVA).

\section{Bespreking van de resultaten op de open vraag}

De open slotvraag heeft betrekking op de (subjectieve) tekortkoming(en) waarvan de instromende CIBA-arts op het moment van de start van de opleiding de meeste hinder had ondervonden. Op deze vraag werd door 78 van de 106 respondenten (74\%) geantwoord.

De rubricering van de gesignaleerde tekortkomingen is weergegeven in tabel 5 .

\section{Discussie en conclusies}

De onderzoeksgroep bestond uit de buitenlandse artsen die in 2004 en 2005 via de CIBA-regeling aan een van de acht medische faculteiten zijn begonnen aan de opleiding

Tabel 1 Respons per universiteit.

\begin{tabular}{|c|c|c|}
\hline Universiteit & Respons & Respons \\
\hline & $\mathrm{N}$ & $\%$ \\
\hline Universiteit van Amsterdam & 13 & 59 \\
\hline Vrije Universiteit & 13 & 65 \\
\hline Rijksuniversiteit Groningen & 9 & 53 \\
\hline Universiteit Leiden & 10 & 59 \\
\hline Universiteit Maastricht & 10 & 67 \\
\hline Radboud Universiteit Nijmegen & 17 & 81 \\
\hline Erasmus Universiteit Rotterdam & 13 & 72 \\
\hline Universiteit Utrecht & 20 & 74 \\
\hline Totaal & 105 & 67 \\
\hline Missing & 1 & 1 \\
\hline Totaal & 106 & 68 \\
\hline
\end{tabular}




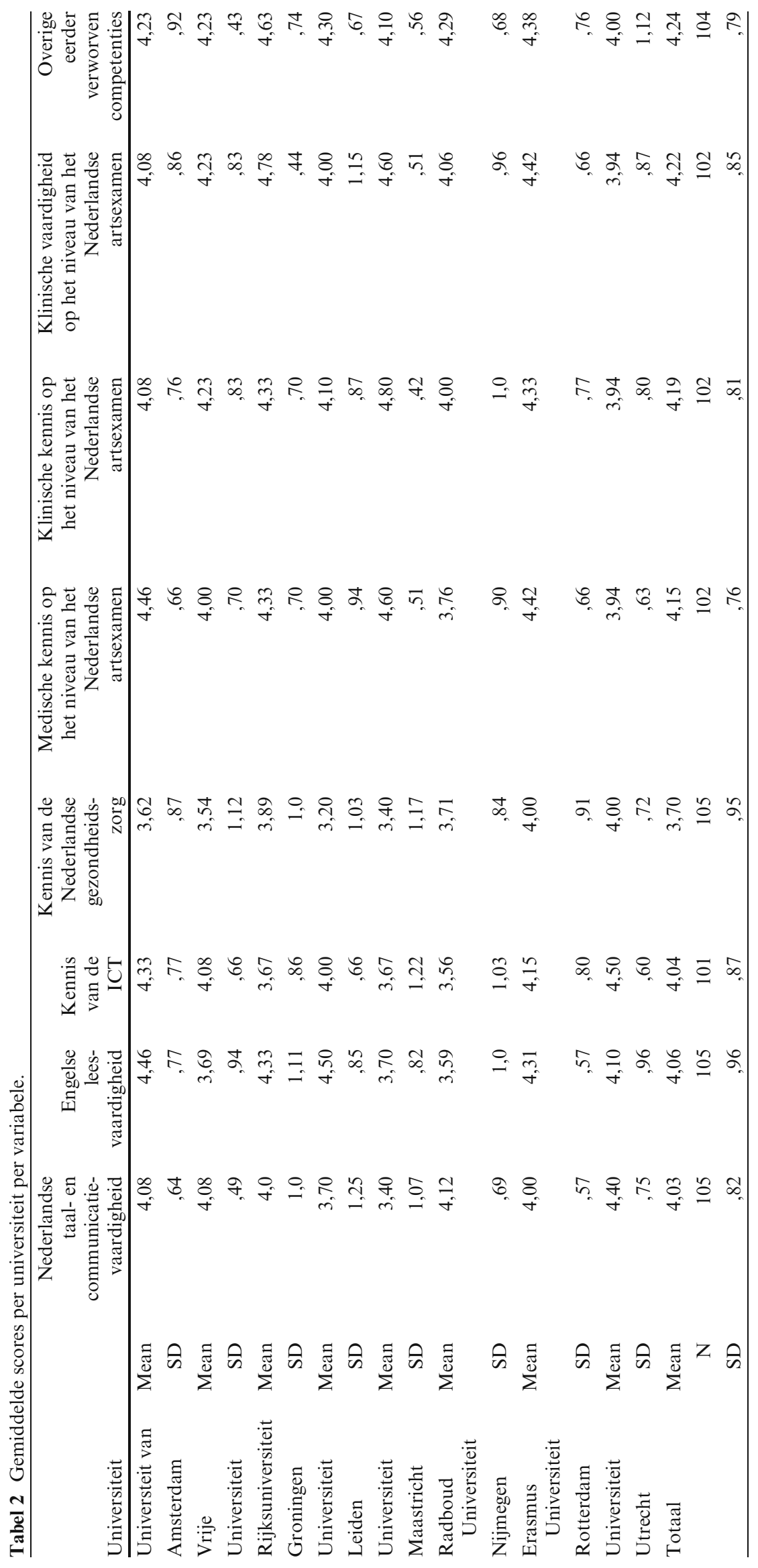


Tabel 3 Gemiddelde scores per variabele over de totale steekproef.

\begin{tabular}{|c|c|c|c|c|c|c|c|c|}
\hline & $\begin{array}{r}\text { Nederlandse } \\
\text { taal- en } \\
\text { communicatie- } \\
\text { vaardigheid } \\
\end{array}$ & $\begin{array}{r}\text { Engelse } \\
\text { lees- } \\
\text { vaardigheid } \\
\end{array}$ & $\begin{array}{r}\text { Kennis } \\
\text { van de } \\
\text { ICT } \\
\end{array}$ & $\begin{array}{r}\text { Kennis van } \\
\text { de } \\
\text { Nederlandse } \\
\text { gezondheids- } \\
\text { zorg } \\
\end{array}$ & $\begin{array}{r}\text { Medische } \\
\text { kennis op het } \\
\text { niveau van } \\
\text { het } \\
\text { Nederlandse } \\
\text { artsexamen } \\
\end{array}$ & $\begin{array}{r}\text { Klinische } \\
\text { kennis op het } \\
\text { niveau van } \\
\text { het } \\
\text { Nederlandse } \\
\text { artsexamen }\end{array}$ & $\begin{array}{r}\text { Klinische } \\
\text { vaardigheid } \\
\text { op het niveau } \\
\text { van het } \\
\text { Nederlandse } \\
\text { artsexamen } \\
\end{array}$ & $\begin{array}{r}\text { Overige } \\
\text { eerder } \\
\text { verworven } \\
\text { competenties } \\
\end{array}$ \\
\hline $\mathrm{N}$ valid & 106 & 106 & 102 & 106 & 103 & 103 & 103 & 105 \\
\hline Missing & 0 & 0 & 4 & 0 & 3 & 3 & 3 & 1 \\
\hline Mean & 4,03 & 4,04 & 4,03 & 3,70 & 4,14 & 4,17 & 4,20 & 4,23 \\
\hline $\mathrm{SD}$ &, 82 & ,98 &, 87 & ,94 &, 76 &, 82 &, 85 &, 80 \\
\hline
\end{tabular}

Tabel 4 Gemiddelde scores per instelling over alle variabelen.

\begin{tabular}{lrrr}
\hline \multicolumn{1}{c}{ Universiteit } & Mean & N & Std. Deviation \\
\hline Universiteit van Amsterdam & 4,18 & 12 &, 40 \\
Vrije Universiteit & 4,10 & 12 &, 41 \\
Rijksuniversiteit Groningen & 4,18 & 8 &, 61 \\
Universiteit Leiden & 3,97 & 10 &, 64 \\
Universiteit Maastricht & 4,01 & 9 &, 27 \\
Radboud Universiteit Nijmegen & 3,90 & 16 &, 51 \\
Erasmus Universiteit Rotterdam & 4,21 & 12 &, 36 \\
Universiteit Utrecht & 4,17 & 18 &, 52 \\
Totaal & 4,09 & 97 &, 47 \\
\hline
\end{tabular}

Tabel 5 Door buitenlandse artsen gesignaleerde tekortkomingen.

Nederlandse taalvaardigheid en communicatie

Lage waardering van het (basis)artsdiploma 37

Zeer trage toelatingsprocedure VWS en CIBA

Lange duur van het aanvullend opleidingstraject

Negatieve benadering CIBA-artsen

Gebrek aan begeleiding aan de universiteit

Ontbrekende kennis van de gezondheidszorg

Samenwerking met arts-assistenten

Geen waardering van het buitenlands specialisme

Weinig patiëntencontacten tijdens aanvullende opleiding

Geen mogelijkheid om kennis te maken met werken in de gezondheidszorg vóór start van de opleiding

Beperkte kennis van de Engelse taal

Ontbreken van ICT-kennis

Combineren van een opleiding met een gezin

Ontbreken van schakelonderwijs

Ontbreken van een valide kennis- of assesssment-toets

Geen kennis van het Limburgs dialect

Cursus Nederlands van ontoereikend niveau

Financiële problemen

Verzorgen van een presentatie

Zeer trage asielproceure

Lange wachttijden tijdens co-schappen

Werken in een team

Weinig klinische ervaring

Weinig kennis van moderne diagnostiek

Gebrek aan zelfstandigheid geneeskunde en niet hebben deelgenomen aan de nieuwe VWS assessment- procedure. De verwachting was dat de mening van de respondenten op weinig punten zou overeenkomen met die van opleiders (Splinter e.a.; ${ }^{3}$ Tromp e. a. ${ }^{7}$ ). Immers, het is denkbaar dat personen die verzocht worden een oordeel uit te spreken over de eigen competenties bij de beantwoording van een dergelijke vraag niet altijd even objectief en oprecht zijn. Daarmee is de betrouwbaarheid van zelfbeoordelingen in het geding. Een studie van Eva et al. ${ }^{9}$ toont aan dat self-assessment matig of zelfs negatief correleert met feitelijke prestaties. De betrouwbaarheid van self-assessment resultaten neemt echter toe als aan de uitkomsten geen zwaarwegende consequenties verbonden worden $\left(\right.$ Gardner $\left.{ }^{10}\right)$. In dit onderzoek was aan de deelnemende artsen/studenten tevoren expliciet meegedeeld dat de gevonden resultaten voor hen geen gevolgen zouden hebben.

Het is zeker mogelijk dat de perceptie van de eigen competenties hoger was dan het oordeel van de opleiders. Direct na verzending van de vragenlijsten hebben zeven van de aangeschreven CIBA-artsen gevraagd of de mogelijkheid bestond alsnog over te stappen naar de nieuwe VWS assessment-procedure; dit waarschijnlijk in de overtuiging dat zij dan nog slechts een programma van 12 weken zouden hoeven te doorlopen. Zij schatten hun competenties kennelijk hoog in. Bij de beantwoording van de vragen hebben zij zich niet laten leiden door sociaal wenselijke antwoorden. Integendeel, iemand die opteert voor een andere route, waarbij kennis getoetst wordt, doet dat uit overtuiging.

De statistische bewerkingen tonen aan dat de buitenlandse artsen van mening zijn dat hun kennis op alle onderdelen van de assessment-procedure redelijk aansloot bij de start van de opleiding geneeskunde. Opleiders verschillen hierin van mening met deze studenten. Zij hebben met regelmaat gerapporteerd dat de beheersing van de Nederlandse taal bij buitenlandse artsen te kort schiet. De scores op de onderdelen van de algemene kennis- en vaardighedentoets lagen lager dan de scores op de onderdelen van de medische kennis- en vaardighedentoets. Maar ook deze verschillen waren niet significant. Voor de overigens geringe verschillen tussen enkele faculteiten 
op de variabelen Nederlandse taal- en communicatievaardigheid en Engelse leesvaardigheid is geen directe verklaring te geven. Mogelijk hangen de verschillen samen met het niveau van het schakelonderwijs dat gevolgd werd voorafgaand aan de aanvullende medische opleiding.

Er zijn in dit onderzoek op de onderzochte variabelen geen significante verschillen tussen de medische faculteiten gevonden. Op alle onderdelen van de medische kennis- en vaardighedentoets (medische en klinische kennis en klinische vaardigheid) zijn de buitenlandse artsen/ studenten van mening dat hun buitenlandse opleiding redelijk aansluit en weinig afwijkt van de Nederlandse geneeskunde opleidingen. Over de mate waarin de mening van de buitenlandse artsen hierover overeenkomt met de realiteit kan geen uitspraak worden gedaan. Bij de open vraag over de ervaren tekortkomingen bij de start van de opleiding geneeskunde constateerde $47 \%$ van de respondenten dat de Nederlandse taal het belangrijkste struikelblok vormde. De extra aandacht die tijdens de opleiding geschonken wordt aan de verbetering van de Nederlandse taal is terecht. Hoewel het algemene oordeel over alle competenties samen een gemiddelde score van 4,09 (ofwel 'sloot redelijk aan') opleverde bleek de kennis van de Nederlandse taal de belangrijkste tekortkoming te zijn, zeker in de beleving van de buitenlandse artsen. Dit vormt een pleidooi voor voortzetting van training van de Nederlandse taal (verdieping en verfijning van het beheersingsniveau) tijdens en na afronding van de opleiding geneeskunde.

Uit dit onderzoek, verricht onder alle buitenlandse artsen die in 2004 en 2005 via de CIBA en direct voor de start van de nieuwe assessment-procedure zijn ingestroomd aan de medische faculteiten in Nederland, blijkt dat zij van mening zijn dat:

1. het niveau van de algemene kennis en vaardigheden (Nederlandse taal- en communicatievaardigheid, Engelse leesvaardigheid, kennis van de ICT, kennis van de gezondheidszorg in Nederland) redelijk aansluit bij de eisen die vanuit de Nederlandse gezondheidszorg gesteld worden. Dit is in tegenstelling tot de opvatting van opleiders.

2. het niveau van de medische kennis- en vaardigheden redelijk aansluit op het niveau van het Nederlandse artsexamen. Ook dit is in tegenstelling tot de opvatting van opleiders.

3. de beheersing van de Nederlandse taal het grootste probleem vormt bij de start van de (aanvullende) opleiding geneeskunde. Deze opvatting wordt gedeeld door opleiders.

Buitenlandse artsen en opleiders verschillen dus met elkaar van mening zowel over het niveau van de algemene als van de medische kennis en vaardigheden. In de nieuwe assessment-procedure worden alle buitenlandse artsen op de genoemde vaardigheden getoetst. Het zijn nu objectieve resultaten die de basis vormen voor de vaststelling van de duur van de aanvullende opleiding. Dat is winst ten opzichte van de situatie die van kracht was voordat de VWS-procedure in werking trad. De professionalisering van de vakbekwaamheidsbeoordeling van buitenlandse artsen was niet alleen een gemeenschappelijke wens van overheid, politici en medische faculteiten, maar ook van belangenorganisaties en van buitenlandse artsen. Buitenlandse artsen hadden kritiek op de ondoorzichtige en subjectieve werkwijze van diplomawaardering door het ministerie van VWS en op de adviserende rol van de Netherlands Universities Foundation for International Cooperation (NUFFIC). ${ }^{11}$

De laatste conclusie, namelijk dat de beheersing van de Nederlandse taal het grootste probleem vormt, ook in de beleving van de buitenlandse artsen, is o.i. van groot belang. Het functioneren van buitenlandse artsen in de Nederlandse gezondheidszorg kan geoptimaliseerd worden als permanente aandacht wordt geschonken aan de verbetering van de beheersing van de Nederlandse taal. Belangenconflict: geen gemeld.

Financiële ondersteuning: geen gemeld

\section{Summary}

A new assessment procedure for foreign medical doctors wishing to practice medicine in the Netherlands replaced the previous procedure (via CIBA, a medical school network) on 1 December 2005 and is now used for all requests for a declaration of professional competence. The procedure comprises: Dutch language and communication skills, reading skills in English, computer skills, knowledge of the Dutch health care system, medical and clinical knowledge and skills at a level equivalent of the Dutch medical degree.

Because medical schools reported that teachers had doubts as to the competencies of the foreign medical doctors, we asked the foreign medical doctors how they themselves perceived their competencies. In the spring of 2006 we approached all 157 foreign medical doctors who had started their additional training according to the CIBA procedure in 2004 and 2005. They were asked to complete a questionnaire with items asking them to rate their competence level in a number of areas at the start of their additional training on a five-point scale.

The response rate was 68\% (106 questionnaires). The results show that the foreign medical doctors deemed their competencies reasonably compatible with the demands of the Dutch health care system. In response to an open question concerning the most serious deficiency at the start of their additional training, the majority (37) of the foreign doctors mentioned difficulties relating to understanding and knowledge of the Dutch language. (Herfs PGP, Kater L, Haalboom JRE. Self perceived competencies of foreign medical doctors at the start of additional medical training in the Netherlands. Dutch Journal of Medical Education 2007;26(4):184-194.)

\section{Literatuur}

Herfs PGP. Erkenning van buitenlandse artsdiploma's; een verhaal apart. Afdeling Studentenzaken; Universiteit Utrecht; 1996. 
Commissie Buitenslands Gediplomeerden Volksgezondheid: Vakbekwaamheid zonder grenzen? Verslag invitational conference Buitenslands Gediplomeerden Volksgezondheid gehouden op 26 maart 2003 te Utrecht. Den Haag; 2003.

Splinter TAW, Herfs PGP, Ruijs AJEM, Luijk SJ van, Wijkhuijs NP. Naar een nieuwe stroomlijn voor buitenlandse artsen; een rapport van de Opleidingscommissie Geneeskunde van het Disciplineoverlegorgaan Medische Wetenschappen (OCGDMW); 2003.

Arkel P van, Engelkes E. Gevluchte arts van wachtkamer naar spreekkamer; een onderzoek naar de mogelijkheden van een efficiëntere instroom van gevluchte artsen in de Nederlandse gezondheidszorg. Stichting voor Vluchteling-studenten UAF. Utrecht; 2003.

Ministerie van Volksgezondheid, Welzijn en Sport (2005): Plan van aanpak Project Assessment buitenslands gediplomeerden gezondheidszorg. Den Haag; 2005.
Merkelbach JW. Supervisie werkt niet voor buitenlandse artsen. Med Contact 1999(54) nr 17.

Tromp F, Rademakers JJDJM, Cate ThJ ten. Development of an instrument to assess professional behaviour of foreign medical graduates. In: Med Educ; 2007 (in press).

Nie NH, Hull CH, Jenkins JG, Steinbrenner K, Bent DH: Statistical Package for the Social Sciences (edition 2). New York: McGraw-Hill 1975.

Eva KW, Cunnington JPW, Reiter HI, Keane DR, Norman GR. How can I know what I don't know? Poor self-assessment in a well-defined domain. Adv Health Sci Educ 2004:9: 211-224.

Gardner D. Self-assessment for autonomous language learners. University of Hong Kong; 1999.

Haaksman D. De NUFFIC onder vuur. In: D\&C Nieuwsbrief; nummer 4. NUFFIC, Den Haag; 2005. 